\title{
The Effects of Explicit Vocabulary Instructions on Secondary ESL Students' Vocabulary Learning
}

\author{
MOHD HANIFF MOHD TAHIR \\ Department of English Language and Linguistics, Akademi Pengajian Bahasa \\ Universiti Teknologi MARA, Perak Branch \\ enifftairy@gmail.com \\ INTAN SAFINAS MOHD ARIFF ALBAKRI \\ Faculty of Languages and Communication \\ Universiti Pendidikan Sultan Idris \\ AIRIL HAIMI MOHD ADNAN \\ Department of English Language and Linguistics, Akademi Pengajian Bahasa \\ Universiti Teknologi MARA, Perak Branch \\ RAFIDAH ABD KARIM \\ Department of English Language and Linguistics, Akademi Pengajian Bahasa \\ Universiti Teknologi MARA, Tapah Branch
}

\begin{abstract}
This study intends to investigate the effect of explicit vocabulary instructions on students' vocabulary learning in Perak. A quasi-experimental research design was employed, and the scores of the pre-and post-tests were analysed using independent sample t-test, paired sample t-test and descriptive statistics. The score comparison and total improvement scores in percentage were also presented. The questionnaires in the student's feedback form were analysed descriptively in terms of their mean scores and standard deviation. The qualitative data from the semi-structured students' interview was transcribed, categorised and coded by using content analysis. The paired sample $t$-test results were $(t=-17.85, d f=29, p<.05)$ for the experimental group and $(t=-4.85, d f=29, p<.05)$ for the control group. Based on the results, the experimental and control groups improved significantly $\left(p=.000^{*}\right)$ in the post-test with a mean difference of 15.62. Thus, the use of different techniques of the explicit method is effective in helping learners to acquire target words. A longitudinal study is recommended to observe the effects of the explicit method of vocabulary instructions if longer time is given for the learners to learn the target words. Such work will indicate whether longer learning period results in better vocabulary knowledge or not. This research extends value in the field of vocabulary learning because it can be used to carry out further investigations in improving the students' ability to learn new words. A possible global extension of this study should be conducted to further determine the power of explicit or other novel vocabulary approaches in advancing students' vocabulary prowess.
\end{abstract}

Keywords: Vocabulary instructions; vocabulary learning; explicit method; target words; ESL learners

\section{INTRODUCTION}

Vocabulary knowledge remains the focal point in English Language teaching (ELT) research, given its uncompromised role in language development and mastery (Lee, Pandian, Rethinasamy, \& Tan, 2019, p. 180). The restricted repertoire of vocabulary information has had a significant impact on the ability of second language learners (L2) to express intended meaning in target language communication (Read, 2004). The shortage of vocabulary materials creates hindrances for the learners of English as a second or foreign language (ESL/EFL) to interact and write using the language. Because of this, they are unable to efficiently read or communicate using English. Such inefficient language use happens in daily tasks as a result of minimal exposure to English language use despite the language's prominence in Malaysia where in accordance with the Malaysian Education Act 1966, English is taught as a second language and in achieving national and international goals, English is also considered as 
important as other subjects in the Malaysian education system (Segawa, 2007). Students continue to face difficulties in using the language properly, due to their inadequate language skills (Salehuddin, Tan, \& Maros, 2006) One suggested way to improve on this situation is by encouraging students to read, as reading books especially in English allows the learners to be able to learn the language (Fatimah \& Vishalache, 2006). Nevertheless, when students are unable to comprehend the books they are reading, the development of their English language skills will be limited. To further complicate the matter, Inderjit (2014) highlighted an alarming trend among Malaysian teenagers where they only read to acquire knowledge for academic reasons rather than developing their own skills. He added that past studies have shown that learners seldom read books to search for information or enjoyment, and their focus is only on preparing for assessments. To worsen the situation, reading as a habit is no longer done, as Malaysians' latest favourite pastime is watching TV and film especially online.

One of the most important skills of English education as is reading and understanding written text (Chang, Lin, \& Abdul Rashid, 2014). However, the results of a study on Form Four students in Malaysia showed the scores of writing skills related to vocabulary, material, organization, and mechanics mostly ranged from 'moderate to bad' (Mukundan, Mahvelati, Mohd Amin Din, \& Nimehchisalem, 2013). It means that high school students face written challenges where one of its probable causes is the lack of vocabulary skills. In addition, Veeramuthu, Wei, and Tajularipin (2011) also indicated that a lack of vocabulary is one of the factors contributing to the poor performance of journal writing skills among second language (L2) students. As a result, they were hindered from expressing their thoughts clearly and effectively in their journal. This is a prevalent occurrence among tertiary level students too, as they grapple with similar writing problems caused by their insufficient vocabulary knowledge, which has resulted in students' poor performances in writing and expressing their ideas in written forms.

In addition, Gass and Selinker (2008) pointed out that lexical errors are the most common errors committed by L2 learners based on the large body of errors and vocabulary training that can determine the success of L2 acquisition. Therefore, it is believed that a learner needs to have a broad vocabulary knowledge that can be taught in many ways to be considered as a good English user. Based on previous studies, it can be concluded that ESL learners need adequate vocabulary learning assistance that can be provided in school during formal lessons. Recognizing the importance of learners' vocabulary skills in classrooms, the Ministry of Education (MOE) has integrated vocabulary learning into the syllabus as well as the KSSM English textbooks used in Malaysian schools. English vocabulary exercises found in the assigned textbooks are some of the tools that educators can use in their English lessons to help their students in vocabulary acquisition. In addition, English teachers were encouraged to search for alternative sources primarily from the internet and newspapers because at times the level of the textbooks is either too difficult or too easy and does not meet the abilities of various students (Hassan \& Selamat, 2002). Not only that, these sources promote greater engagement and are also deemed as more interactive, which is one crucial aspect of language learning as "interactive tasks present learners with the opportunities to experience interesting and enjoyable lessons and thereby ensure that their motivation is sustained." (Lee, Krishnamoorthy, \& Rong, 2019, p.12).

In the English syllabus used in Malaysia as underlined in the Standard Based Curriculum for Secondary School (KSSM), although vocabulary is included as one of the components in the lessons, the focus remains on the four core language skills which are reading, writing, listening, and speaking. Vocabulary learning is only incorporated in an ad hoc basis, and the teachers implicitly teach the target words as they are illustrated with the grammar and sound system in the language content. While this matter may suggest an awareness of unfamiliar words among the students on the surface, they are still urged to seize every chance 
of learning a new word, particularly during English lessons in school. This situation however presents some vocabulary-related issues among students. One example is in evaluating the alternative meaning that a word and its spelling can be accounted for. As they are unable to notice the difference, this has become a matter of confusion among learners. Another common issue among learners is inappropriate word choice (Saadiah \& Kaladevi, 2009). This is due to the approach used in learning target words that are used in sentences during English lessons, and it is assumed that learners can find out the contextual meaning on their own. What is more, in acquiring a language, learners need opportunities for producing outputs, participating in oral practices and using of new words as Swain (2000) maintained that the likelihood of learning will increase when learners reflect on the form and meaningful communication they have experienced while using a language.

Meanwhile, Alamri and Rogers (2018) investigated the use of an explicit method of vocabulary teaching on seventy Arabic undergraduates who were English learners. They disclosed that for instance, in an immediate vocabulary test after using this explicit method, the students from the experimental group gained a higher mean score $(47.8 \%)$ than the control group who learned vocabulary in a traditional way (16.4\%). Not only that, in a delayed test to measure the retention of this newly acquired vocabulary, the experimental group once again outperformed the control group with a higher mean score (43.4\% and $18.7 \%$ respectively). They then claimed the benefit of explicit method of vocabulary instructions over merely teaching vocabulary implicitly.

Interestingly, studies have also recognized the role of an explicit method of vocabulary instruction as a compatible companion to the implicit method. In a study on a group of Saudi Arabian college students who were simultaneously taught English vocabulary explicitly and implicitly, Al-Darayseh (2014) discovered that the students who were put in the experimental group received a higher total mean score $(M=28.75)$ in a Post-test as opposed to the control group who only learned the vocabulary through the traditional implicit approach $(M=20.10)$. Additionally, the performance of the experimental group's students in a reading comprehension Post-test ( $M=15.07)$ has also exceeded those of the control group $(M=10.59)$. Furthermore, in a vocabulary Post-test after the intervention stage, the experimental group once again outran the control group in terms of their score ( $M=12.71$ and 8.79 respectively). Because of this, $\mathrm{Al}-$ Darayseh (2014) implored that "the combination of explicit and implicit vocabulary strategies has proved to be effective in increasing students' vocabulary size, and as a result, in improving their reading comprehension skills." (p.1114).

In a similar vein, Fainman and Tokar (2019) recently advocated that both explicit and implicit and methods of vocabulary teaching should not have to exist exclusively of each other in a language learning setting. In studying the use of explicit, implicit, and blended vocabulary teaching approaches among three groups of undergraduate students of an aviation university in Ukraine who were learning the English language, they maintained that in terms of immediate vocabulary acquisition, the students who received the explicit treatment still statistically surpassed the other two treatment groups in the Post-test, based on immediate word acquisition (the mean score for Explicit, $M=79.41$; Blended, $M=79.0$; and Implicit, $M=63.17$ ). Surprisingly, the results of a delayed test demonstrated that blended instruction (which combined both explicit and implicit methods) is the most efficient approach in terms of vocabulary retention as compared to a solely implicit or explicit teaching method. Not only that, the blended group has also managed to increase their mean score to 81.16 for the delayed test while the other two groups produced a decreased score (Explicit, $\mathrm{M}=77.5$; and Implicit, $M=62.50$ ). Because of this, they then suggested that as the blended approach seemed to be superior to both explicit and implicit approaches, "English classroom practices should incorporate a balanced approach employing both implicit and explicit vocabulary instructions." (p.110). 


\section{THEORETICAL FRAMEWORK}

In the theoretical framework, the independent variable (input) is explicit vocabulary instructions, while the dependent variable (output) is the learning of target words whether the target vocabulary is learned or not. On the other hand, the intervention stage in the theoretical framework includes functional tasks (interactional and non-interactional), based on the theories of Piaget, Vygotsky, and Bruner, as well as the input processing levels which consist of the Level Processing Theory and Krashen's Feedback and Affective Filter Hypothesis where it is an abstract mechanism occurring internally in the mind of the learners. The theoretical framework is presented as follows:

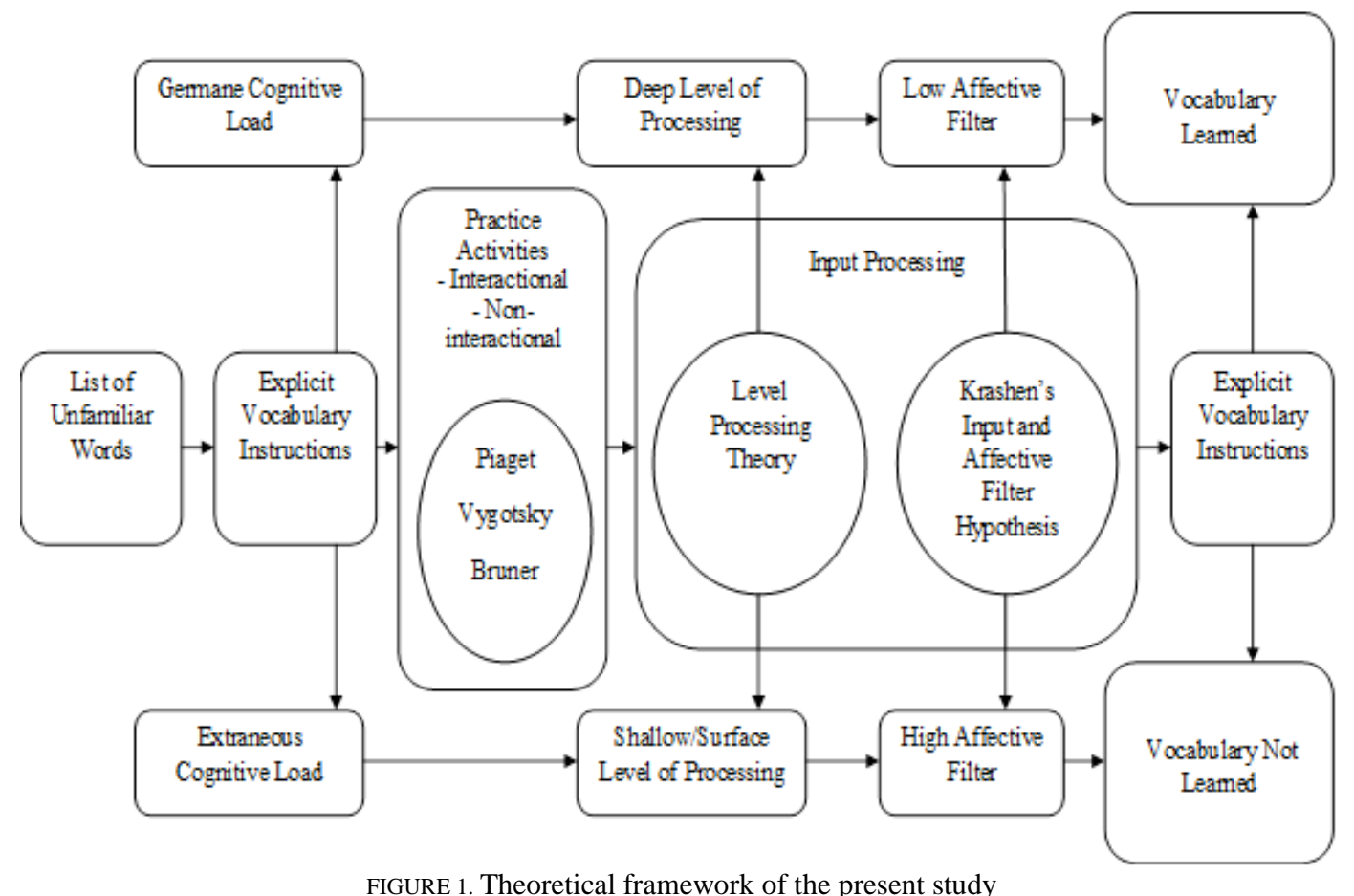

RESEARCH OBJECTIVES, QUESTIONS, AND HYPOTHESIS

The present study aims to highlight the importance of considering the explicit method of vocabulary instructions for vocabulary learning among Form Two learners in the classroom. In investigating the results of using the explicit method using the available techniques to teach and learn vocabulary at school, it is also vital to know the interests of the students. Therefore, it is essential to understand how the experiences of students learning the target words have affected them in developing their vocabulary skills by using the explicit approach.

The research objectives included the following:

1. To investigate the effectiveness of using the explicit method to learn vocabulary for Form Two learners.

2. To discover Form Two learners' preferences among the techniques used to learn vocabulary.

Based on these objectives, two research questions are presented:

1. How effective is the use of the explicit method of learning vocabulary for Form Two learners?

2. Which techniques of the explicit method to learn vocabulary are preferred by Form Two learners? 
As part of an experimental study, the research hypotheses below were tested:

H0: There is no significant improvement in the learners' knowledge of the target words after receiving the vocabulary instruction using the explicit method.

H1: There is a significant improvement in the learners' knowledge of the target words after receiving the vocabulary instruction using the explicit method.

\section{METHODOLOGY}

60 Form Two ESL learners (two groups) were chosen to participate in this study. The students were tested before and after receiving the explicit or implicit vocabulary instructions in learning the target words (Pre- or Post-tests) to assess how far the explicit approach has helped them in learning new words as opposed to the implicit method of vocabulary instructions. In this study, five research instruments were used: A Pre-test, explicit vocabulary lessons, a Student's Feedback Form, a Post-test, and a Semi-structured Students' Interview session. The questionnaires were used to provide answers from a relatively large number of groups, while interviews were used to examine the opinions, behaviours, and experiences of people in detail. Wallace (1997) suggested that the ideal way to incorporate these two approaches (questionnaire and interview) is to maximize the advantages of both methods. In this analysis, the independent variable (input) is the explicit vocabulary instructions, while the dependent variable (output) is the learning of the target words whether the words were acquired or not. The aim of this research is to discover the relationship between the variables indicated by the researchers and to decide whether the explicit method of vocabulary instruction is effective in helping the participants to develop their vocabulary knowledge.

\section{PARTICIPANTS}

The participants in this study were two groups of Form Two students (60 students) from two different schools located in different localities, one is in Ipoh, Perak (an urban area) and the other is in Teluk Intan, Perak (a suburban area). The main reason for choosing these participants is because these Form Two participants did not sit for the Form Three Assessment (PT3) examination in the same year this study was conducted and have been exposed for nearly one year to lessons conducted using the English Language's Standard Based Curriculum for Secondary School (KSSM). They were also selected based on their previous English Language final year exam results when they were in Form One. The participants were also similar in terms of their results, as they obtained a mean score of 40.53 in the exam, indicating a D+ grade (40.00-49.00). These similarities are important to avoid the risk of jeopardizing internal validity, where diverse previous experience of the learners may relate to the subjects investigated in the study (Chua, 2012). On the other hand, it can be seen that these participants had a poor level of English language command, as only a modest pass was obtained by them. It is feared that learners with a lack of ability to interpret words (Stanovich, 1992), weak comprehension abilities (Gough \& Hillinger, 1980) and syntactic processing, limited understanding and vocabulary skills (Wiseheart, Altman, Park, \& Lomardino, 2009) are at high risk of academic failure. These students were therefore chosen in investigating the effects of using the explicit method of vocabulary instruction on their vocabulary learning. Meanwhile, each group was taught by a sole English teacher and these English language teachers have been teaching English in the selected schools for more than 10 years. 


\section{MATERIALS AND INSTRUMENTS}

For this analysis, the following instruments were used:

1. The Pre-test.

2. Explicit vocabulary lessons.

3. The Post-test.

4. The Student's Feedback Form.

5. The Semi-structured Students' Interview.

The Pre-test is a proficiency test to determine the participants' initial vocabulary score. In the Pre-test, the participants were given 15 short reading texts where the synonyms or same meaning phrases of target words were used in the sentences. 45 multiple-choice questions created for the Pre-test were assigned into 15 different reading texts consisting of three questions each. The participants were required to answer all 45 multiple choice questions within 30 minutes. They were not informed on the subsequent explicit vocabulary lessons and the Post-test to ensure that they will not give more attention than they should to the words which appeared in the Pre-test. This is to ensure the validity of the tests. The Pre-test was checked and validated by an English language Master Teacher from a secondary school.

Explicit vocabulary instructions were developed into 10 sessions of vocabulary lessons for the participants in the experimental group: 'Pictorial Vocabulary', 'Crossword Puzzles', 'Frayer Model', 'K.I.M. Strategy', 'Making Meaning', 'Wordsplash', 'Vocabulary Anchors', 'Vocabulary Cartoons', 'Vocabulary Frames', and 'Spelling'. These lessons were designed to help the participants in learning the target words by using the explicit method. A senior teacher with a rich 20 years of experience in teaching English to lower secondary form learners from a school was appointed to check and validate the lesson plans. This is to ensure that the lesson plans are valid and reliable.

The Post-test is the proficiency test to determine the participants' final score. The Posttest actually used the same items from the Pre-test, but changes were made in terms of the arrangement of the texts to avoid learners from giving memorised answers from their Pre-test. The Pre- and Post-tests are instruments used to measure the learners' performance in learning the target words and determine whether it is significantly different or not. The Post-test was also checked and validated by an English language Master Teacher from a secondary school.

The Student's Feedback Form was disseminated after each vocabulary lesson to determine the participants' perceptions in the experimental group. They were required to circle on the numbers ranging from ' 1 ' to ' 5 ' to represent their responses ( 1 for 'totally disagree'; 2 for 'disagree'; 3 for 'neither agree nor disagree'; 4 for 'agree'; 5 for 'totally agree') for each statement. This Student's Feedback Form was checked and validated by a Senior Lecturer in a university. Besides that, it was also tested against the Cronbach's Alpha internal consistency reliability analysis to ensure its reliability.

The Semi-structured Students' Interview was conducted with selected learners in the experimental group to clarify the findings from the questionnaires and further support the quantitative data collected earlier. Related questions on the topics included in this Semistructured Students' Interview are on the participants' personal perceptions, experiences, opinions, preferences, and ideas. The interview session was recorded by using an audiotape recorder. After that, the researchers transcribed the audio data into the written form for documentation purposes. The interview questions were checked and validated by a lecturer from one of the public universities in Malaysia. 


\section{RESEARCH PROCEDURES}

The researchers listed 45 words to be learned before the procedure. All participants sat for a Pre-test on vocabulary. A specific system of vocabulary instructions was given to the participants in the experimental group. By using the 'Pictorial Vocabulary' worksheet designed for the first lesson, the students were exposed to the target words, followed by nine other vocabulary lessons. The instructions on vocabulary were divided into 10 sessions of explicit lessons on vocabulary by using these techniques: 'Pictorial Vocabulary', 'Crossword Puzzles', 'Frayer Model', 'K.I.M. Strategy', 'Making Meaning', 'Wordsplash', 'Vocabulary Anchors', 'Vocabulary Cartoons', 'Vocabulary Frames', and 'Spelling'. After each vocabulary lesson, a feedback form was distributed to the experimental group's participants to explore their perception of the vocabulary lesson using these explicit approaches On the other hand, 10 regular English lesson sessions were held for the control group where the target words were implicitly learned by the participants in this class. All participants sat for an immediate recall test (Post-test) consisting of 45 predetermined target words identified by the researchers after the final English lesson. The purpose of the Post-test is to show their understanding of the meaning of a word in the form of multiple-choice questions and their ability to actively remember a word in context.

This study was conducted within a span of 22 weeks in about 6 months. The participants were exposed on a weekly basis to the vocabulary lesson (one lesson per week) to ensure that the learners continuously learn the target words. This can help minimize the risk to the credibility of the research. The estimated lesson time was about 40 minutes for each group. The participants were given 30 minutes to answer all questions for the Pre- and Post-tests, and they were expected to fill the Student's Feedback Form within 5 to 10 minutes after they completed the tasks. In addition, 10 to 15 minutes was allocated for the interview sessions with the selected participants.

\section{DATA ANALYSIS METHOD}

The qualitative data was analysed using the SPSS statistical software version 24 . The effects of using the explicit approach of vocabulary instructions to the participants' learning of target words were determined by contrasting their Pre- and Post-test scores. This will indicate whether there is a significant improvement in their vocabulary learning. In addition, the Preand Post-test vocabulary scores were also evaluated using the independent samples t-test, paired-samples t-test, descriptive statistics, combined with mean scores and standard deviation. Apart from that, the total percentage improvement scores were determined to assess how the participants have performed in their respective vocabulary performance tests. The data obtained from the questionnaires (Student's Feedback Form) were analysed descriptively in terms of the mean and standard deviation of responses for each item, in addition to the vocabulary scores.

With respect to the qualitative data, a Semi-structured Students' Interview session was conducted at the final phase of the study to gather additional information about the experiences and perceptions of students about their learning of the target words. Their responses were transcribed and documented, before they were classified and coded by the researchers according to relevant categories or themes. This has allowed the researchers to qualitatively obtain rich information to be used in explaining the findings of the quantitative data. 


\section{RESULTS}

TABLE 1. Independent samples t-test for the Pre-test of the experimental and control group

\begin{tabular}{lccccc}
\hline Pre-test & $\begin{array}{c}\text { Mean score } \\
(\mathrm{M})\end{array}$ & $\begin{array}{c}\text { Standard deviation } \\
(\mathrm{SD})\end{array}$ & $\mathrm{t}$ & $\mathrm{df}$ & $\begin{array}{c}\text { Sig. } \\
(2 \text {-tailed })\end{array}$ \\
\hline Experimental group $(\mathrm{N}=30)$ & 16.67 & 5.27 & 1.024 & 29 & .314 \\
Control group $(\mathrm{N}=30)$ & 15.23 & 6.01 & & & \\
\hline
\end{tabular}

Based on Table 1, the mean score for the experimental group was $M=16.67$ and the mean score for the control group was $M=15.23$. For both groups, the mean difference ( $M$ difference) was 1.44. In contrast, the findings of the independent samples t-test indicated an insignificant difference $(t=1.024, \mathrm{df}=29, \mathrm{p}>.05)$. This shows that there was no significant difference in the control and experimental group's Pre-test. Thus, the participants' Pre-test results for both groups were nearly similar. In terms of their knowledge of the target words prior to the experimental treatment, the participants were of the same degree.

On the other hand, Tables 2 and 3 provide descriptive statistics for the experimental group's Pre and Post-tests:

TABLE 2. Descriptive statistics for the Pre and Post-tests of the experimental group

\begin{tabular}{lcccc}
\hline Experimental group & $\begin{array}{c}\text { Mean score } \\
(\mathrm{M})\end{array}$ & $\begin{array}{c}\text { Standard deviation } \\
(\mathrm{SD})\end{array}$ & M difference & $\begin{array}{c}\text { Total improvement } \\
\text { score (\%) }\end{array}$ \\
\hline Pre-test & 16.7 & 5.27 & 21.9 & 131.1 \\
Post-test & 38.6 & 6.25 & & \\
\hline
\end{tabular}

TABLE 3. Descriptive statistics for the Pre and Post-tests of the control group

\begin{tabular}{lcccc}
\hline Control group & $\begin{array}{c}\text { Mean score } \\
(\mathrm{M})\end{array}$ & $\begin{array}{c}\text { Standard deviation } \\
(\mathrm{SD})\end{array}$ & M difference & $\begin{array}{c}\text { Total improvement } \\
\text { score (\%) }\end{array}$ \\
\hline Pre-test & 15.2 & 6.01 & 6.4 & 42.1 \\
Post-test & 21.6 & 10.45 & & \\
\hline
\end{tabular}

Table 2 shows the descriptive statistics for the experimental group's Pre- and Post-tests. The experimental group's mean score for the Pre-test was $M=16.7$. Using the explicit method through the vocabulary lessons, their mean score for the Post-test was determined after this group learned the target words and it was $\mathrm{M}=38.6$. The mean differences indicated an increase of 21.9 mean score from the experimental group's Pre-test to the Post-test. The total percentages improvement score was up by 131.1 percent.

Table 3 displays the control group's Pre- and Post-test descriptive statistics. The control group's mean score for the Pre-test was $M=15.2$. This group naturally learned the target words through normal English lessons before they sat down for the Post-test. Their mean score for the Post-test was calculated and it was $M=21.6$. The mean differences indicated an increase of 6.4 mean score from the control group's Pre-test to the Post-test. The total percentage improvement score was only 42.1 percent.

In addition, the scores between the experimental and control group's Pre and Post-tests were compared. For both groups respectively, the performance comparison (improved, declined and the same score) of the students is reported in Table 4:

TABLE 4. Score comparison between the Pre and Post-tests of the experimental and control group

\begin{tabular}{lccc}
\hline Group & Learners with improved score & Learners with declined score & Learners with same score \\
& $(\%)$ & $(\%)$ & $(\%)$ \\
\hline Experimental & 100 & 0 & 0 \\
& $(30$ learners $)$ & $(0$ learner $)$ & $(0$ learner $)$ \\
Control & 80 & 17 & 3 \\
& $(24$ learners $)$ & $(5$ learners $)$ & $(1$ learner $)$ \\
\hline
\end{tabular}


Table 4 shows the comparison of the score (improved, declined or the same score) between the experimental group's Pre- and Post-tests. After learning the target words using the explicit method through the vocabulary lessons, all 30 participants (100 percent) within this group were able to improve. This suggests that all participants in the experimental group have improved in terms of their grades in the Post-test relative to the Pre-test, demonstrating the usefulness of using the explicit method of vocabulary instructions to learn target words among the experimental group learners.

On the other hand, for the control group participants who implicitly learned the target words through normal English lessons before sitting for the Post-test, there were 24 participants (80 percent) who received a higher score in the Post-test. Surprisingly in the Post-test, there were five participants (17 percent) with a decreased score, while one participant (three percent) obtained the same score between the Pre- and Post-tests. It could then be deduced that the control group's participants had inconsistent results as they naturally learnt the target words through normal English classes. This shows that this method might not be working as it is supposed to for every participant, particularly for those participants who have obtained lower or equivalent results in the Post-test compared to the Pre-test.

Table 5 and 6 show the results of the paired sample t-test for the experimental and control group's Pre and Post-tests:

TABLE 5. Paired samples t-test for the Pre and Post-tests of the experimental group

\begin{tabular}{|c|c|c|c|c|c|}
\hline Experimental group & $\begin{array}{c}\text { Mean score } \\
(\mathrm{M})\end{array}$ & $\begin{array}{c}\text { Standard deviation } \\
(\mathrm{SD})\end{array}$ & $\mathrm{t}$ & df & $\begin{array}{c}\text { Sig. } \\
\text { (2-tailed) }\end{array}$ \\
\hline Pre-test $(\mathrm{N}=30)$ & 16.67 & 5.27 & -17.854 & 29 & .000 \\
\hline Post-test $(\mathrm{N}=30)$ & 38.63 & 6.25 & & & \\
\hline
\end{tabular}

TABLE 6. Paired samples t-test for the Pre and Post-tests of the control group

\begin{tabular}{|c|c|c|c|c|c|}
\hline Control group & $\begin{array}{l}\text { Mean score } \\
\text { (M) }\end{array}$ & $\begin{array}{c}\text { Standard deviation } \\
\text { (SD) }\end{array}$ & $\mathrm{t}$ & $\mathrm{df}$ & $\begin{array}{c}\text { Sig. } \\
\text { (2-tailed) }\end{array}$ \\
\hline Pre-test $(\mathrm{N}=30)$ & 15.23 & 6.01 & -4.851 & 29 & .000 \\
\hline Post-test $(\mathrm{N}=30)$ & 21.57 & 10.45 & & & \\
\hline
\end{tabular}

Table 5 points out the findings of the paired sample t-test for the experimental group's Pre and Post-tests. The mean score of the participants for the Pre-test was $M=16.67$ and $M=$ 38.63 for the Post-test. For the Pre- and Post-tests, the mean difference (M difference) was 21.96. The paired sample $t$-test statistical findings showed a significant difference $(t=-17.854$, $\mathrm{df}=29, \mathrm{p}<.05)$. After the experimental treatment, the participants' scores in the experimental group have increased significantly. Therefore, the null hypothesis is rejected, and the alternative hypothesis is accepted.

On the other hand, Table 6 shows the results of the control group's paired samples t-test of the Pre- and Post-test. The mean score of the participants for the Pre-test is $M=15.23$ and $M=21.57$ for the Post-test. For the Pre- and Post-tests, the mean difference (M difference) was 6.34. The paired sample $\mathrm{t}$-test statistical findings showed a significant difference $(\mathrm{t}=-4.851$, $\mathrm{df}=29, \mathrm{p}<.05)$. Therefore, after the experimental treatment, the scores of the control group's participants increased significantly. Nevertheless, for the experimental group, the performance change (the $M$ difference) surpassed the control group by 15.62. This suggested that the experimental group intervention was more successful than the control group as more target words were learned by the participants in the experimental group compared to the control group within the same time period. 
Table 7 provides a brief summary of the Student's Feedback Form's analysis:

TABLE 7. Brief summary of an analysis of Student's Feedback Form

\begin{tabular}{lcccc}
\hline Vocabulary lesson & $\begin{array}{c}\text { Mean score } \\
\text { for item (M) }\end{array}$ & $\begin{array}{c}\text { Standard deviation } \\
\text { for items (SD) }\end{array}$ & $\begin{array}{c}\text { Mean score } \\
\text { for rating (M) }\end{array}$ & $\begin{array}{c}\text { Standard deviation } \\
\text { for rating (SD) }\end{array}$ \\
\hline Pictorial Vocabulary & $3.267-4.600$ & $0.498-1.022$ & 4.400 & 0.621 \\
Crossword Puzzles & $3.233-4.333$ & $0.568-0.999$ & 4.033 & 0.809 \\
Frayer Model & $3.167-4.500$ & $0.461-0.774$ & 4.467 & 0.507 \\
Vocabulary Anchors & $3.133-4.300$ & $0.507-1.125$ & 4.000 & 0.947 \\
Vocabulary Cartoons & $3.367-4.467$ & $0.466-0.817$ & 4.433 & 0.504 \\
Vocabulary Frames & $3.367-4.433$ & $0.466-0.794$ & 4.500 & 0.572 \\
K.I.M. Strategy & $3.933-4.300$ & $0.484-0.834$ & 4.333 & 0.547 \\
Wordsplash & $3.333-4.500$ & $0.466-0.925$ & 4.400 & 0.498 \\
Making Meaning & $3.367-4.600$ & $0.490-0.791$ & 4.300 & 0.750 \\
Spelling & $3.367-4.500$ & $0.556-0.794$ & 4.467 & 0.571 \\
\hline
\end{tabular}

The experimental group's participants showed positive perceptions of all the explicit method techniques presented in this study through the vocabulary lessons. This can be seen in the results for each vocabulary lesson in Table 7 of the Student's Feedback Form analysis. Based on the mean ratings, all items in the Student's Feedback Form showed a high rate of constructive participant responses ( $\mathrm{M}=3.668$ to 5.000). The mean for all lessons rating was also high ( $\mathrm{M}=3.668$ to 5.000$)$ with less than 1.000 standard deviations. In addition, 'Vocabulary Frames' lesson is the most preferred lesson among the participants $(\mathrm{M}=4.500, \mathrm{SD}=0.572)$ and 'Vocabulary Anchors' is the least preferred lesson among them $(\mathrm{M}=4.000, \mathrm{SD}=0.947)$, although they are in favour of all explicit method techniques in this study.

\section{FINDINGS FROM THE SEMI-STRUCTURED STUDENTS’ INTERVIEW}

10 experimental group learners were interviewed by the researchers. All five male students and five female students were 14 years old. All of them possessed a low level of language skills and had very little English language knowledge. The participants responded positively on three dimensions which are the vocabulary lessons, personal experiences, and instructor's instructions. They stated that they were satisfied with the vocabulary lessons as they were able to learn the target terms in their class with the aid of an instructor. In addition, to promote effective learning, they believed that the vocabulary lessons must be built according to the needs of the students. This will ensure a good personal experience of the students in learning the target words by using the explicit method of vocabulary instructions.

\section{DISCUSSION}

With respect to the first research question on the effectiveness of using the explicit method of vocabulary instructions to learn vocabulary for Form Two learners, both groups showed an increase in the mean scores in the Post-test. Although both groups showed an improvement, the total percentage improvement rating for the experimental group was a whopping 89 percent above the control group. For the experimental group, the score improvement (the M difference) also exceeded the control group by 15.62. In contrast, the control group's participants have inconsistent results as not all their scores were changing from their Pre-test to Post-test. This further exemplifies the success of the participants in this study who were using the explicit method of vocabulary instructions to learn the target words.

Mirzaii (2012) reported a similar result, while suggesting that both Implicit Vocabulary Learning (IVL) and Explicit Vocabulary Learning (EVL) had significantly helped the 
participants to improve on their Post-test. The experimental group, however, surpassed the control group in terms of their percentage change score in the current study. It shows that the explicit approach of vocabulary learning is more effective when compared to the implicit approach for the participants to learn the target words. Learners are thought to learn more efficiently using the explicit method where teachers may integrate the explicit method into their English language lessons to enhance the ability of learners to learn the target words. Potentially, it is suggested that teachers use the specific approaches involving the 'Vocabulary Frames', 'Spelling', 'Pictorial Vocabulary', and 'Vocabulary Cartoon' lessons as they are proven to be effective and beneficial among learners based on the outcome of this research. Ultimately, it will contribute substantially to the growth of the vocabulary skills of the learners when the number of English words learned increases significantly, allowing them to use and understand English in reading, writing, listening, and speaking while leading to more developed English language skills.

Hashemzadeh's previous study (2012) also found that the vocabulary retention of EFL learners improved significantly by using various types of exercise. Moreover, in his research with the use of games, Luu (2012) exposed the experimental group in the recollection of vocabulary activities that resulted in the experimental group exceeding the control group during the immediate retention stage and the delayed retention stage in the recollection vocabulary. Mohd Tahir and Tunku Mohtar (2016) meanwhile encouraged teachers to give learners more opportunities to experience words through their preferred vocabulary learning activities such as the explicit method suggested here to promote better retention and deeper understanding of unfamiliar words. Consequently, in order to be stored in their long-term memory, the vocabulary items intended for the learners should be presented through various techniques of the explicit approach instructions so that it can be easily remembered and retrieved. The teachers therefore should plan various types of vocabulary tasks and activities and provide the learners with more realistic opportunities through explicit vocabulary instructions.

In addition, Dimas (2011) who studied the L2 (English) content-area course on explicit vocabulary training suggested that the 'Word Study' notebook helped teacher trainees learn vocabulary through their active involvement in classroom teaching and learning sessions. On the other hand, the current study included using the 'Pictorial Vocabulary' worksheet as a reference for the experimental group's participants to help them complete the tasks and activities created throughout the vocabulary instructions. This is aimed at scaffolding the needs of the learners to improve the learning of the target words. The learners should refer to the worksheet on 'Pictorial Vocabulary' while completing the tasks given as the target words' annotation and connotation were also included. This will help them to better remember and understand the target words to be stored in their long-term memory. Mohd Tahir and Tunku Mohtar (2016) also recommended that visual aids should be employed to help students in learning the target words. As a result, the learning effectiveness of the target words among the learners can be optimized. Nonetheless, the learners need to use the same words learned from time to time to familiarize themselves with the use of the words and to not forget them easily.

Interestingly, Feng and Horn's research (2012) on the impact of centred vocabulary training on reading understanding highlighted a different outcome compared to other studies. They indicated that there was no significant difference in the learning of vocabulary or comprehension of reading between the control and experimental classes, and only insignificant small variations in reading comprehension improvements were found among the participants of the study. Although Feng and Horn (2012) reported conflicting findings, many previous studies (Hashemzadeh, 2012; Yip \& Kwan, 2006; Luu, 2012; Madrigal-Hopes, Villavicencio, Foote, \& Green, 2014; Dimas, 2011; Mirzaii, 2012) showed that the explicit method of vocabulary instructions could work for learners to learn the target words. 
This is further cemented by the researchers' interview with 10 participants chosen from the experimental group, in which it is deduced that the explicit form of vocabulary instructions has helped them to learn the target words better. Several studies in addition have shown that the explicit approach helps learners to understand the target words better than the implicit method. This is because the explicit approach deals with the presence of learners of different language skills. The learners with a low level of vocabulary awareness used the explicit approach to significantly benefit from learning the target words. Based on the findings, teachers should consider using the explicit method of learning the target terms for learners with low language skills, as it is proven to be successful based on the results of previous studies.

Regarding the second research question, the experimental group participants indicated positive perceptions of all techniques of the explicit method of learning vocabulary presented in this study through the vocabulary lessons. This can be seen in the results for each vocabulary lesson in the analysis of the Student's Feedback Form. The 'Vocabulary Frames' lesson was also given five stars by half of the participants (15 learners) $(\mathrm{M}=4.500 ; \mathrm{SD}=0.572)$. On the other hand, just nine learners (30 percent) gave five stars $(\mathrm{M}=4.00 ; \mathrm{SD}=0.947)$ for the 'Vocabulary Anchors' lesson.

During the interview session, the participants claimed that 'Vocabulary Frames' and 'Spelling' are their favourite vocabulary lessons, where they wanted to do more of the same vocabulary lessons. On the contrary, 'Vocabulary Anchors' is their least favourite vocabulary lesson, as they indicated that it was difficult to understand the instructions and it was hard to complete the tasks in the lesson. Despite this, the participants are in favour of all techniques of the explicit method of learning vocabulary within the scope of this study. Teachers then should use a variety of techniques to teach target words because one technique may be more effective to learners than the other. Furthermore, focusing only on a single technique can cause the learners to get bored and demotivated as it does not challenge them or occasionally trigger their interest. It is therefore recommended that teachers use a variety of techniques to teach the target words, particularly the one included in the lessons of 'Vocabulary Frames', 'Spelling', 'Pictorial Vocabulary', and 'Vocabulary Cartoons', as these lessons are beneficial among the learners in this study.

Bahrani, Tam, and Nekoueizadeh (2014) meanwhile proposed that exposure to language input is important to second language acquisition (SLA), and students who learn English as a second or foreign language are encouraged to engage in all kinds of enjoyable and informative lessons to acquire language knowledge within the environment of the classroom as they encourage vocabulary retention. In the current study for example, the participants were exposed to various techniques of the specific approach to learn the target terms in the classroom. The various vocabulary instructions and features added into the lessons in the current study enhanced their usefulness as a method for learning new words. A variety of fun and stimulating tasks were presented to the learners where they had to use certain strategies and forms to complete them. Consequently, due to a high degree of motivation, the students can learn the target words better as they were supported by the various methods used to teach the target words. Hence, developing an interesting and fun vocabulary lesson is critical for teachers as it will stimulate the interest of learners to actively engage in the lesson. The learners' vocabulary skills will also be improved by the successful learning of the target words.

Moreover, according to Craik and Lockhart (1972), for the learners to acquire knowledge, they must be introduced to the questions that are at least one level higher than their current knowledge, so that they can use their previous knowledge to solve the presented questions. In other words, the understandable feedback must be one step beyond the current ability of the learner, defined as ' $i+1$ '. This will test and improve their cognitive ability. The learners must learn and maintain the target vocabulary in their long-term memory in this matter so that it can easily be recalled in the future. For example, they will find it difficult to spell a 
word during the Spelling class as it is the first time they encounter the word. However, they will slowly understand the meaning of the word after listening to the definition and the use of the word in context. It includes some scaffolding, where instructions and support are provided to the learners to understand the meaning and use of the word in context. Eventually, when the word's spelling is recognized and corrected, they can obtain a full word-related information. They may try hard to memorize the word, especially when they are interested in the words, so they can use the word on a regular basis. According to Krashen (1982), when the affective filter is weak, learners will be able to learn new vocabulary. Basically, they have expanded their vocabulary skills as they learn new words. This therefore shows the importance of using the explicit approach to learn the target words

Based on the findings of this research, it is found that after obtaining vocabulary instructions using the explicit method, there is a significant improvement in the learners' awareness of the target words. The learners have benefitted extensively from the use of the explicit approach to learn the target words. Therefore to facilitate the growth of the learners' vocabulary skills, teachers and curriculum designers should consider integrating the use of this explicit approach. This is especially true for students with poor English language skills. Ultimately, it will help to increase the level of their overall vocabulary and language skills, as Meganathan, Thai, Paramasivam, and Jalaluddin (2019) argued that "adequate vocabulary knowledge is crucial for successful language learning and language use.” (p. 52).

\section{CONCLUSION}

Based on the results of this research, it can be concluded that the use of the explicit method of vocabulary instructions is successful in the learning of the target words among the Form Two students selected for this study. The participants are able learn the target vocabulary by using the explicit method as it is deemed as more effective. This is because the target words are stored in their long-term memory, in which to successfully answer the questions in the Post-test, they should remember the target words. The hypothesis was formed due to the higher scores attained in the Post-test relative to the participants' response to the Pre-test.

This research also suggests that the use of various techniques within the explicit approach built through the vocabulary lessons has enabled the participants to learn the target words better, thereby increasing their vocabulary knowledge. All this while, the vocabulary was taught to the participants indirectly during the English lessons. However, the findings of this study have indicated that it is necessary for vocabulary to be addressed directly to the students, particularly to those with a limited level of language skills. In addition, various vocabulary learning strategies can be sourced around, and educators should strive to provide differentiated instructions in order to accommodate their students' diverse needs. Explicit method of vocabulary instructions could be one of those strategies, and the teachers and curriculum developers should include this approach to improve the vocabulary knowledge of the students.

A longitudinal study is recommended in future to observe the effects of the explicit method of vocabulary instructions in improving the students' vocabulary skills if the students are given a longer time to learn the target words. In general, this study also adds value to the field of knowledge in vocabulary learning as it can be used to carry out further investigations to enhance the capacity of the students in acquiring new words. The study could also be extended internationally in comparing the explicit vocabulary instructions with new materials or approaches in vocabulary instructions aimed at encouraging learners to expand their vocabulary knowledge. 


\section{ACKNOWLEDGEMENTS}

It is a great pleasure for me to appreciate many individuals' support and efforts to making this research a success. My sincere appreciation goes to Assoc. Prof. Dr Intan Safinas, my supervisor, for her valuable and critical feedback, valuable advice, and her continuous care and support throughout my years of study. Her great support has helped me to complete this paper through many difficulties. I would like to thank my colleagues, Dr Airil Haimi and Dr Rafidah for the constant effort, persistence and encouragement as their positive comments have made it possible for me to complete this research. This research did not receive any particular grant from any government, commercial, or non-profit funding agency.

\section{REFERENCES}

Alamri, K. \& Rogers, V. (2018). The effectiveness of different explicit vocabulary-teaching strategies on learners' retention of technical and academic words. The Language Learning Journal, 46(5), 622-633.

Al-Darayseh, A. A. (2014). The impact of using explicit/implicit vocabulary teaching strategies on improving students' vocabulary and reading comprehension. Theory and Practice in Language Studies, 4(6), 11091118.

Bahrani, T., Tam, S. S. \& Nekoueizadeh, M. (2014). Second language acquisition in informal setting. Theory and Practice in Language Studies, 4(8), 1714-1723.

Chang, K. L., Lin, S. E. \& Abdul Rashid, M. (2014). Benchmarking Year Five students' reading abilities. English Language Teaching, 7(5), 50-58.

Chua, Y. P. (2012). Mastering research method. Shah Alam: McGraw-Hill.

Craik, F. I. M., \& Lockhart, R. S. (1972). Levels of processing: A framework for memory research. Journal of Verbal Learning and Verbal Behaviour, 11, 671-684.

Dimas, H. M. S. (2011). Explicit vocabulary instruction in an English content-area course with university student teachers: When comprehensible input needs to be comprehended. Gist Education Learning Research Journal, 5, 84-103.

Fainman, I. \& Tokar, Y. (2019). Explicit, implicit, and blended vocabulary instruction: Efficiency in an Aviation English Course. Collegiate Aviation Review International, 37(2), 110-132.

Fatimah, H., \& Vishalache, B. (2006). Language immersion for language proficiency ESL learners: The Alemac Project. Reading Matrix, 6(2), 44-56.

Feng, J., \& Horn, M. (2012, April). Effect of focused vocabulary instruction on $7^{\text {th }}$ graders' reading comprehension. Paper presented at the 2012 Chinese American Educational Research and Development Association Annual International Conference, Vancouver.

Gass, S. M., \& Selinker, L. (2008). Second language acquisition: An introductory course (3 ${ }^{\text {rd }}$ ed.). New York: Taylor \& Francis.

Gough, P. B., \& Hillinger, M. L. (1980). Learning to read: An unnatural act. Bulletin of the Orton Society, 30, 179-196.

Hashemzadeh, M. (2012). The effect of exercise types on EFL learners' vocabulary retention. Theory and Practice in Language Studies, 2(8), 1716-1727.

Hassan, F., \& Selamat, N. F. (2002). Why aren't students proficient in ESL: The teachers' perspective. The English Teacher, 18-29.

Inderjit, S. (2014). Reading trends and improving reading skills among students in Malaysia. International Journal of Research in Social Sciences, 3(5), 70-81.

Krashen, S. (1982). Principles and practice in second language acquisition. Oxford: Pergamon Press.

KSSM English Language Curriculum Specifications. (2016). Ministry of Education, Malaysia.

Lee, B. C., Pandian, A, Rethinasamy, S., \& Tan, D. A. L. (2019). Effects of PWIM in the ESL classroom: Vocabulary knowledge development among primary Malaysian learners. 3L: The Southeast Asian Journal of English Language Studies, 25(4), 179-197. DOI: http://doi.org/10.17576/3L-2019-250411

Lee, M. C. L., Krishnamoorthy, K., \& Rong, Y. J. (2019). The role of negotiated interaction in L2 vocabulary acquisition among primary ESL learners. 3L: The Southeast Asian Journal of English Language Studies, 25(2), 1-21. DOI: http://doi.org/10.17576/3L-2019-2502-01

Luu, T. T. (2012). Vocabulary recollection through games. Theory and Practice in Language Studies, 2(2), 257264. 
Madrigal-Hopes, D. L., Villavicencio, E., Foote, M. M., \& Green, C. (2014). Transforming English language learners' work readiness: Case studies in explicit, work-specific vocabulary instruction. Adult Learning, 25(2), 47-56.

Meganathan, P. M., Thai, Y. N., Paramasivam, S., \& Jalaluddin, I. (2019). Incidental and intentional learning of vocabulary among young ESL learners. 3L: The Southeast Asian Journal of English Language Studies, 25(4), 51-67. DOI: http://doi.org/10.17576/3L-2019-2504-04

Milton, J. (2008). Vocabulary uptake from informal learning tasks. Language Learning Journal, 36(2), $227-237$.

Mirzaii, M. (2012). Implicit vs explicit vocabulary learning: Which approach serves long-term recall better? The Southeast Asian Journal of English Language Studies, 18(2), 1-12.

Mizumoto, A., \& Takeuchi, O. (2009). Examining the effectiveness of explicit instruction of vocabulary learning strategies with Japanese EFL university students. LanguageTeaching Research, 13(4), 425-449.

Mohd Tahir, M. H., \& Tunku Mohtar, T. M. (2016). The effectiveness of using vocabulary exercises to teach vocabulary to ESL/EFL learners. Pertanika Journal of Social Sciences and Humanities, 24(4), 16511669.

Mukundan, J., Mahvelati, E. H., Mohd Amin Din, \& Nimehchisalem, V. (2013). Malaysian secondary school students' ESL writing performance in an intensive English program. World Applied Sciences Journal, 22(12), 1677-1684.

Nam, J. (2010). Linking research and practice: Effective strategies for teaching vocabulary in the ESL classroom. TESL Canada Journal, 28(1), 127-135.

Nezhad, G., \& Shokrpour, N. (2012). The impact of task type and cognitive style on vocabulary learning. English Language Teaching, 5(9), 17-23.

Read, J. (2004). Research in teaching vocabulary. Annual Review of Applied Linguistics, 24, 146-161.

Saadiah, D., \& Kaladevi, S. (2009). Error analysis of the written English essays of secondary school students in Malaysia: A case study. European Journal of Social Sciences, 8(3), 483-495.

Salehuddin, K., Tan, K.H., Maros, M. (2006). Definiteness and Indefiniteness: A Contrastive Analysis of the use of determiners between the Malay language and English. GEMA Online Journal of Language Studies, 6(1), 21-30.

Segawa, N. (2007). Malaysia's 1996 Education Act: The impact of a multiculturalism-type approach on national integration. SOJOURN: Journal of Social Issues in Southeast Asia, 22(1), 30-56.

Stanovich, K. E. (1992). Speculation on the causes and consequences of individual differences in early reading acquisition. In Gough, P., Ehri, L., \& Treiman, R. (Eds.), Reading acquisition. Hillsdale: NJ Laurence Erlbaum.

Swain, M. (2000). The output hypothesis and beyond: Mediating acquisition through collaborative dialogue. In Lantolf, J. (Eds.), Sociocultural theory and second language learning. Oxford: Oxford University Press.

Veeramuthu, V., Wei, H. S., \& Tajularipin, S. (2011). The effect of scaffolding technique in journal writing among the second language learners. Journal of Language Teaching and Research, 2(4), 934-940.

Wallace, M. J. (1997). Action research for language teachers. Cambridge: Cambridge University Press.

Wiseheart, R., Altmann, L., Park, H., \& Lomardino, L. (2009). Sentence comprehension in young adults with developmental dyslexia. Annals of Dyslexia, 59, 151-167.

Yip, W. M., \& Kwan, C. M. (2006). Online vocabulary games as a tool for teaching and learning English vocabulary. Educational Media International, 43(3), 233-249. 